\title{
Dural ectasia of the optic nerve sheath: is it always benign?
}

This article was published in the following Dove Press journal:

Eye and Brain

19 November 2009

Number of times this article has been viewed

\section{Berker Bakbak' \\ Hava Dönmez ${ }^{2}$ \\ Tülay Kansu ${ }^{3}$ \\ Hayyam Kiratli ${ }^{4}$}

'Hacettepe University Institute of Neurological Sciences and Psychiatry, Neuro-ophthalmology Unit, Ankara,

Turkey; ${ }^{2}$ Diskapi Yildirim Beyazid Education and Research Hospital Neurology Clinic, Ankara, Turkey; ${ }^{3}$ Hacettepe University Medical Faculty, Department of Neurology, NeuroOphthalmology Unit, Ankara, Turkey; ${ }^{4}$ Hacettepe University Medical Faculty, Department of Ophthalmology, Ocular Oncology Unit, Ankara, Turkey

Correspondence: Berker Bakbak Hacettepe University Institute of Health Science, Sihhiye 06100, Ankara, Turkey Tel +90 533546573 I

Email drberkerbakbak@yahoo.com
Abstract: A 36-year-old woman with a 3-month history of progressive visual loss had papilledema, dilatation of the optic nerve sheaths and normal cerebrospinal fluid pressures. She was diagnosed as dural ectasia of the optic nerve sheaths and surgical decompression was performed. In this case report, severe visual loss is described as a serious complication of this rare disease and the importance of early surgical intervention is emphasized.

Keywords: optic nerve, dural ectasia, meningocele

\section{Introduction}

Optic nerve dural ectasia is saccular dilatation of the optic nerve sheath. It is characterized by expansion of the cerebrospinal fluid (CSF) around the optic nerve without orbital or cerebral neoplasm and inflammation..$^{1-3}$ The terms; optic hydrops, primary cyst of the optic nerve sheath, patulous subarachnoid space, cystic hygroma, arachnoid cyst, perioptic subdural hygroma, and dural ectasia of the optic nerve sheath all have been used to describe this entity since its first description in $1918{ }^{1,2,4}$ The term optic nerve sheath meningocele was introduced by Garrity et al in $1990 .{ }^{1}$ We prefer the term dural ectasia to describe the optic nerve sheath dilatation. Imaging of the orbit using magnetic resonance imaging (MRI) in patients with dural ectasia reveals tube-like enlargement of the optic nerve/sheath complex. ${ }^{1,2}$ We present a patient with rapidly progressive visual loss which was related to dural ectasia of the optic nerve sheath and the vision remained unchanged despite surgical treatment.

\section{Case report}

A 36-year-old female was admitted (to the Department of Neurology, Hacettepe University Medical Faculty, Department of Neurology, Neuro-ophthalmology Unit, Ankara, Turkey) with the complaints of headache and severe bilateral visual loss that had progressed rapidly in 3 months. She was found to have papilledema on examination and had been treated with acetazolamide $250 \mathrm{mg}$ qid for 8 weeks elsewhere. Idiopathic intracranial hypertension (IIH) was considered in diagnosis although opening pressure was recorded normal in the lumbar puncture (LP). On our examination her visual acuity (VA) was light perception OD and 20/100 OS. There was a right afferent pupillary defect. Fundoscopy revealed pale optic nerve head with blurred margins on the right and chronic disc edema on the left. She was not able to identify any of the Ishihara color plates OU. LP

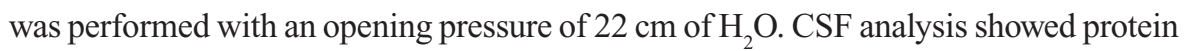
level of $40 \mathrm{mg} / \mathrm{dL}$ and no cells. MRI studies revealed a fluid-filled dilated optic nerve 
sheath surrounding the optic nerves (Figure 1). There was no evidence of a space-occupying lesion. Her left VA decreased to counting fingers in a week. The CSF pressure at the repeat LP was significantly low which could not be recorded. Dural ectasia of the optic nerve is considered in diagnosis. Due to progressive dysfunction of the optic nerve despite treatment with carbonic anhydrase inhibitors, optic nerve sheath decompression via medial transconjunctival approach was performed bilaterally by an ophthalmic surgeon (HK). The distal part of the orbital portion of the optic nerve was found to be significantly enlarged and had a bulb-like appearance. The dura was streched but otherwise looked normal. Overlying dural vessels were also enlarged and tortuous. Three parallel longitudinal incisions, each measuring 2 to $2.5 \mathrm{~mm}$ in length, were made into the dura along the enlarged optic nerve. Large amount of clear fluid rapidly egressed with pressure following the first incision. The optic nerves deflated within seconds while cerebrospinal fluid continued to ooze for a while. No intraoperative complications were observed. The left optic disc edema resolved within one week and the patient remained stable over the next 3 months with the same visual acuity.

\section{Discussion}

A dilatation of the optic nerve sheath could be secondary to neoplasms and malformations of the orbit, like gliomas, meningiomas and arachnoid cysts involving the optic nerve sheath. ${ }^{1,2}$ Dural ectasia of the optic nerve is a rare cause

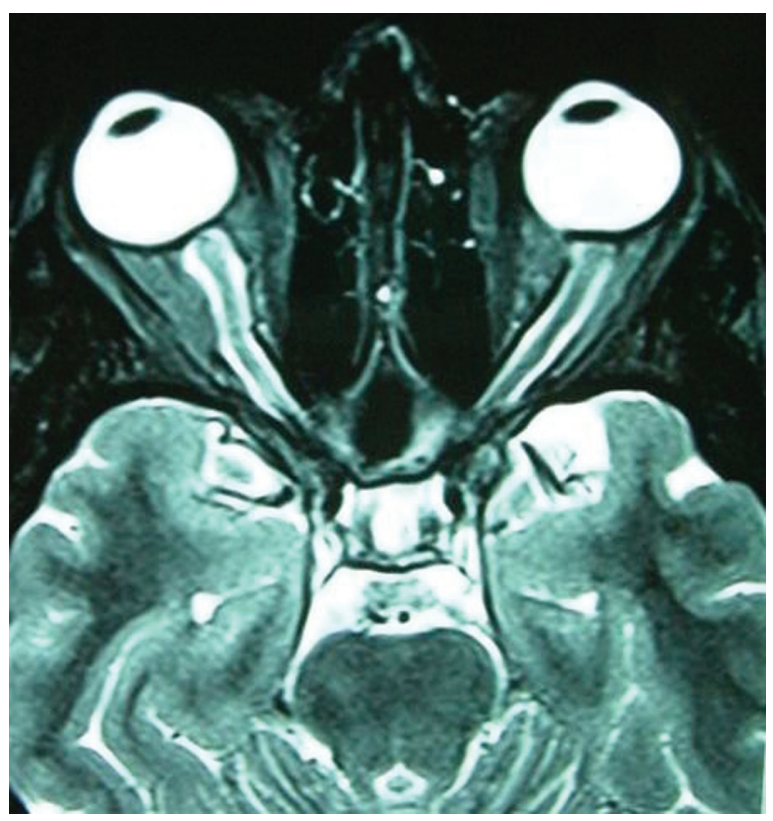

Figure I Fluid-filled dilated sheath surrounds normal optic nerves on T2-weighted axial MRI. of optic nerve sheath enlargement due to the accumulation of CSF around the optic nerve with no associated pathology. The radiological examination of choice is MRI with fat suppression and high spatial resolution which shows tubelike enlargement of the optic nerve sheath isointense with cerebrospinal fluid. ${ }^{2}$ Optic nerve glioma can be associated with thickening and distention of the optic nerve which is in contrast with the appearence of meningocele. Optic nerve sheath meningioma should also be considered in the differential diagnosis because of its "railroad track" appearance of the optic nerve. ${ }^{4}$ Clinical examination, CSF analysis, MRI, investigations including full blood count, anti-nuclear antibodies, erythrocyte sedimentation rate, folate, serum B12 and serum angiotensin converting enzyme levels in our patient revealed no evidence of any other systemic disease or abnormalities around the optic canal.

Papilledema and optic nerve sheath enlargement can also be seen with IIH. ${ }^{5-7}$ There are some common features of both diseases; however there is no significant evidence suggesting the role of raised intracranial pressure in the etiology of the dural ectasia of the optic nerve. ${ }^{1,8}$ Although optic nerve sheath dilatation is one of the radiological features of $\mathrm{IIH}$, the enlargement of the optic nerve sheath to this degree is unusual. The clue for differential diagnosis is the LP opening pressure which should be more than $250 \mathrm{~mm} \mathrm{H}_{2} \mathrm{O}$ in IIH. ${ }^{9}$ At no time our patient had an elevated CSF pressure, including 3 lumbar punctures.

Patients with optic nerve meningocele may present with headache, and transient or permanent visual loss. ${ }^{1}$ Ocular findings other than papilledema have been reported as progressive hyperopia, choroidal folds and cystoid macular edema. ${ }^{1,8,10}$

More than 30 patients with optic nerve sheath meningocele have been described in the literature..$^{1-4,11,12}$ The largest series included 13 cases. ${ }^{1}$ All patients presented with visual complaints and three patients had visual acuity worse than 20/200. ${ }^{1}$ Three out of 13 patients had neurofibromatosis type 1 (NF1). Two other case reports also described the ectasia of the perioptic dural sheath as an unusual and benign manifestation of NF1. ${ }^{4,12}$ Thus, most common association with dural ectasia of optic nerve sheath appears to be NF1. A case report and the review of the literature in 1997, disclosed total of 31 cases with optic nerve meningocele. ${ }^{2}$ Optic nerve decompression surgery have been performed in 13 of these cases. Although visual acuities were not recorded in all patients, 7 cases showed no visual improvement despite the decompression surgery. ${ }^{2}$ Spooler et al described a child with multipl congenital abnormalities and optic nerve meningocele that 
progressively expanded and caused displacement of the orbit and complete blindness. ${ }^{11}$

The most reasonable explanation for the development of the optic nerve sheath meningoceles comes from Hayreh's studies who investigated the relationship of the optic nerve sheath to the optic nerve and stated that congenital narrowing of the optic or congenital cranio-orbital junction anomalies could cause optic nerve sheath meningocele. ${ }^{13}$

Treatment of dural ectasia of the optic nerve sheath depends on optic nerve functions. Carbonic anhydrase inhibitors may be beneficial in some cases. ${ }^{10}$ The effects of corticosteroids are not mentioned in the literature. In cases with persistent papilledema, surgical decompression should be considered in the treatment. ${ }^{8}$

In summary, dural ectasia of the optic nerve is an enlargement of the orbital optic nerve sheath, diagnosed by MRI studies and can follow benign or sometimes an unfavorable course. The striking feature of our patient was rapidly progressive visual loss without any mass lesion or intracranial hypertension. The surgical decompression did not improve but preserved the remaining vision. Early surgical decompression of the optic nerve sheath in these patients who present with progressive optic nerve dysfunction may improve vision or prevent the progression.

\section{Disclosures}

The authors report no conflicts of interest.

\section{References}

1. Garrity JA, JC Trautmann, GB Bartley, et al. Optic nerve sheath meningoceles. Clinical and radiographic features in 13 cases with a review of the literature. Ophthalmology. 1990;97:1519-1531.

2. Lunardi P, Farah JO, Ruggeri A, Nardacci B, Ferrante L, Puzzilli F. Surgically verified case of optic sheath nerve meningocele: case report with review of the literature. Neurosurg Rev. 1997;20:201-205.

3. Jungkim S, Khurshid SG, Fenton S. Dural ectasia of the optic nerve sheath. Acta Ophthalmol Scand. 2005;83:266-267.

4. Lövblad KO, Remonda L, Ozdoba C, Huber P, Schroth G. Dural ectasia of the optic nerve sheath in neurofibromatosis type 1:CT and MR features. J Comput Asist Tomogr. 1994;18:728-730.

5. Agid R, Farb RI, Willinsky RA, Mikulis DJ, Tomlinson G. Idiopathic intracranial hypertension: the validity of cross-sectional neuroimaging signs. Neuroradiology. 2006;48(8):521-527.

6. Helmke K, Hansen HC. Fundamentals of transorbital sonographic evaluation of optic nerve sheath expansion under intracranial hypertension. II. Patient study. Pediatr Radiol. 1996;26:706-710.

7. Kesler A, Yaffe D, Shapira M, Kott E. Optic nerve sheath enlargement and reversal of optic nerve head in pseudotumor cerebri. Harefuah. 1996;130(7):457-459, 503.

8. Shanmuganathan V, Leatherbarrow B, Ansons A, Laitt R. Bilateral idopathic optic nerve sheath meningocele associated with unilateral transient cystoid macular oedema. Eye. 2002;16:800-802.

9. Friedman DI, Jacobson DM. Diagnostic criteria for idiopathic intracranial hypertension. Neurology. 2002;59(10):1492-1495. Review.

10. Mesa-Gutierrerez JC, Quinones SM, Ginebreda JA. Optic nerve sheath meningocele. Clin Ophthalmol. 2008;2(3):661-664.

11. Spooler JC, Cho D, Ray A, Zouros A. Patient with congenital optic nerve meningocele presenting with left orbital cyst. Childs Nerv Syst. 2009;25:267-269

12. Nikas I, Theofanopoulou M, Lampropoulou P, Pourtsidis A, Hadjigeorgi C, Kosmidis H. Optic pathway glioma associated with orbital rhabdomyosarcoma and bilateral optic nerve sheath dural ectasia in a child with neurofibromatosis-1. Pediatr Radiol. 2006;36:1200-1203.

13. Hayreh SS. The sheath of the optic nerve. Ophthalmologica. 1984; 189:54-63.
Eye and Brain

\section{Publish your work in this journal}

Eye and Brain is an international, peer-reviewed, open access journal focusing on clinical and experimental research in the field of neuroophthalmology. All aspects of patient care are addressed within the journal as well as basic research. Papers covering original research, basic science, clinical and epidemiological studies, reviews and evaluations,

Submit your manuscript here: http://www.dovepress.com/eye-and-brain-journal

\section{Dovepress}

guidelines, expert opinion and commentary, case reports and extended reports are welcome. The manuscript management system is completely online and includes a very quick and fair peer-review system, which is all easy to use. Visit http://www.dovepress.com/testimonials.php to read real quotes from published authors. 